\title{
Proteinase-Activated Receptor-2 Expression in Breast Cancer and the Role of Trypsin on Growth and Metabolism of Breast Cancer Cell Line MDA MB-231
}

\author{
R. MATĚJ ${ }^{1}$, P. MANĎÁKOVÁ ${ }^{2}$, I. NETÍKOVÁ ${ }^{3}$, P. POUČKOVÁ ${ }^{4}$, T. OLEJÁR ${ }^{4}$ \\ ${ }^{1}$ Department of Pathology, Thomayer Teaching Hospital, ${ }^{2}$ Institute of Pathology and Molecular \\ Medicine, Second Medical Faculty, Charles University, ${ }^{3}$ Department of Oncology, First Medical \\ Faculty, Charles University and ${ }^{4}$ Institute of Biophysics, First Medical Faculty, Charles University, \\ Prague, Czech Republic
}

Received date February 2, 2006

Accepted date July 28, 2006

On-line available date August 22, 2006

\begin{abstract}
Summary
Proteinase-activated receptor-2 (PAR-2) is a ubiquitous surface molecule participating in many biological processes. It belongs to the family of $\mathrm{G}$ protein-coupled receptors activated by the site-specific proteolysis of trypsin and similar proteases. Altered function of PAR-2 has been described in different malignant tumors. In the present study, we investigated the expression of PAR-2 in breast cancer surgical specimens and the role of trypsin in breast cancer cell line MDA MB-231 proliferation and metabolism. A total of 40 surgical samples of infiltrative ductal breast cancer and breast cancer cell line were included in this study. We analyzed PAR-2 expression by immunohistochemistry, RT-PCR and western blot. Activation of PAR-2 on cell line MDA MB-231 was measured using calcium mobilization assay determined by flow cytometry. MTT cell metabolism assay and cell count analysis were used to assess the trypsin influence on breast cancer cell line MDA MB-231 proliferation. Immunohistochemical examination showed the expression of PAR-2 in all samples of breast cancer surgical specimens and high levels of cell lines which was confirmed by RT-PCR and western blot. Calcium mobilization assay corroborated the activation of PAR-2 on cell line MDA MB-231 either by trypsin or by an agonistic peptide. Cell metabolism assay and cell count analysis showed significant differences of proliferative activity of breast cancer cells dependent on the presence or absence of trypsin and serum in the culture medium. PAR-2 is expressed by high levels in infiltrative ductal breast cancer tissue specimens. PAR-2 is also strongly expressed in studied breast cancer cell lines. PAR-2 is activated by trypsin and also by agonistic peptide in the model of breast cancer cell line MDA MB-231. Activation of PAR-2 in vitro influences proliferative and metabolic activity of breast cancer cell line MDA MB-231. The action of trypsin is modified by the presence of serum which is a potential source of protease inhibitors.
\end{abstract}

Key words

Breast cancer $\bullet$ PAR-2 $\bullet$ Trypsin $\bullet$ Expression 


\section{Introduction}

The role of different proteinases and their inhibitors in cancer development and malignant behavior and the relationship of these enzymes to the prognosis of cancer is constantly discussed. The role of tissue matrix metalloproteinases, cathepsins and other enzymes produced by cancer cells has been extensively investigated (Hojilla et al. 2003, Leeman et al. 2003, Roshy et al. 2003). However, many other enzymes are produced by malignant cells and/or tumor-associated cells such as fibroblasts or immunocompetent cells. One of these enzymes, trypsin, is a proteinase produced not only by exocrine pancreatic and intestinal Paneth's cells, but also by other epithelial tissues (bronchial epithelium) or connective brain cells (glia) (Minn et al. 1998, Cederqvist et al. 2003). Enhanced production of trypsin was reported in malignant cells (Uchima et al. 2003). Recently, a new function of this enzyme in cancer progression and development has been investigated. Trypsin and similar enzymes, such as mast cell tryptase or coagulation factor $\mathrm{Xa}$, act on the cell surfaces via specific receptors. The action of these enzymes is physiologically regulated by peptides called antiproteases, normally present in the blood serum.

Proteinase-activated receptor-2 (PAR-2) is ubiquitous surface molecule participating in many biological processes. It belongs to a family of $\mathrm{G}$ proteincoupled receptors (PAR's) activated by tethered ligand sequences within the amino terminal part of the molecule that is made accessible by the site-specific proteolysis. PAR-2 activation after the site-specific proteolysis of $\mathrm{N}$-terminal end by trypsin and presentation of tethered ligand sequence (SLIGKV) to extracellular domains of the receptor participates in the tissue growth and differentiation, regeneration and repair, inflammatory response regulation and also in malignant transformation (Macfarlane et al. 2001).

Infiltrative breast carcinoma is one of the most common human malignancies. Following standardized criteria it is possible to score the prognostic factors which depend on the histopathological grade and expression of several regulatory proteins (e.g. progesterone receptor, estrogene receptor and c-erb B2) (Rosai 2004).

The aim of our study was to characterize the expression of PAR-2 receptor in breast cancer tissue in surgical samples of infiltrative ductal breast carcinoma with correlation to histopathological grade of the tumors and to the expression of other prognostic factors (estrogen and progesterone receptors). In the model of breast cancer cell line MDA MB-231, we studied the possibility of activation of PAR-2 receptor by trypsin and agonistic peptide (SLIGKV). The role of trypsin on the cell line metabolism and proliferative activity was assessed by MTT cell metabolism assays and cell count analysis.

\section{Material and Methods}

\section{Breast cancer samples}

Forty peroperative surgical samples of infiltrative ductal carcinomas were frozen in liquid nitrogen and routinely processed for histopathological examination. During this diagnostic procedure, additional two sets of 20 sections ( $10 \mu \mathrm{m}$ thick) were collected in sterile Eppendorf tubes, frozen in liquid nitrogen and stored at $-80{ }^{\circ} \mathrm{C}$ for extraction of nucleic acids and proteins. Definitive diagnosis of infiltrative breast cancer was confirmed by microscopic evaluation of histological slides from formaline-fixed, paraffin-embedded tissue samples. Standardized criteria were used to evaluate the prognostic factors (Table 1).

Table 1. Breast cancer surgical samples specification

\section{Histopathological grade}

$\begin{array}{ll}\text { Grade I } & 15 \\ \text { Grade II } & 12 \\ \text { Grade III } & 13 \\ \text { Total } & 40\end{array}$

\section{Expression of prognostic factors}

\begin{tabular}{ll} 
Estrogen receptor & 32 \\
Progesterone recptor & 30 \\
$P$-53 protein & 25 \\
c-erb B2 protein & 30 \\
Total & 40 \\
\hline
\end{tabular}

\section{Cell cultures}

MDA MB-231 and MCF-7 breast cancer cell lines were maintained in Dulbecco's Modified Eagle Medium (DMEM) with high glucose, supplemented with $10 \%$ fetal calf serum (FCS) and gentamicin in concentration $40 \mu \mathrm{g} / \mathrm{ml}$. Cells were cultured according to a routine procedure. 


\section{Immunohistochemistry}

Microscopic tissue slides (5 $\mu \mathrm{m}$ thick) were deparaffinized, rehydrated and boiled in a citrate buffer (pH 7.6) $3 \times 5$ min in a microwave oven. Endogenous peroxidase was blocked with a water solution containing $0.01 \%$ natrium azide and $1 \%$ hydrogen peroxide. Nonspecific positivity was blocked by rabbit serum in TBS (150 $\mu \mathrm{l} / 10 \mathrm{ml})$ for $30 \mathrm{~min}$.

The slides were incubated overnight in $4{ }^{\circ} \mathrm{C}$ with the goat polyclonal primary antibody mapping the new $\mathrm{NH}_{2}$ terminal of human PAR-2 (clone N-19, sc-8206 Santa Cruz Biotechnology) diluted 1:500 in 5\% fetal bovine serum in TBS. The detection of immunostaining was performed using the Envision ${ }^{\circledR}$ kit and diaminobenzidine was used as a chromogen. Slides incubated with secondary antibody only and with nonspecific isotype-matched primary antibodies were used as controls of specificity. Mayer's hematoxylin was used as a nuclear counterstain. As a negative control, slides of a breast cancer sample were incubated with nonspecific isotypematched primary antibodies and with secondary antibody only.

\section{Western blotting analysis}

The deeply frozen breast cancer tissue or cell suspension of breast cancer cell lines were homogenized, dissolved in 2X Tris-glycine SDS sample buffer (Novex) and boiled for $5 \mathrm{~min}$. The concentration of total protein was measured spectrophotometrically using BSA kit (Pierce) following manufacturer's instructions. Equally, $20 \mu \mathrm{g}$ of protein was fractioned on the SDS-PAGE and blotted on nitrocellulose membrane (S\&S NC) using Mini TransBlott ${ }^{\circledR}$ Cells (BioRad). After visualization by Poceau S staining (Sigma) membranes were blocked with $5 \%$ nonfat dried milk in PBS with $0.1 \%$ Tween 20 at 4 ${ }^{\circ} \mathrm{C}$ overnight. Goat polyclonal primary antibody (PAR-2 (N-19): sc-8206 Santa Cruz Biotechnology) was diluted $1: 1000$ in $5 \%$ nonfat milk in T-PBS. The filters were incubated for $1 \mathrm{~h}$ and washed $6 \mathrm{x}$ for $10 \mathrm{~min}$ in T-PBS. The secondary antibody, peroxidase-conjugated (AffiniPure Rabbit Anti-Goat IgG (H+L), Jackson ImmunoResearch Laboratories) was diluted 1:10 000 in T-PBS. The filters were incubated for $45 \mathrm{~min}$ and washed in T-PBS six times for $10 \mathrm{~min}$. Peroxidase activity was detected by Amersham's ECL+, following the manufacturer's protocol. Breast cancer sample incubated without primary antibody served as a negative control.

\section{RT PCR}

Deeply frozen breast cancer tissue and MDA MB-231 and MCF-7 breast cancer cell lines were homogenized (approx. $50 \mathrm{mg}$ ). Total RNAs were isolated using TRIzol ${ }^{\circledR}$ Reagent (Life Technologies, GIBCO BRL) according to the producer's protocol. Concentration of RNA was determined by spectrophotometer at 280/260 nm. Primers (Smith-Swintosky et al. 1997) for PAR-2 were 5'-TTGCCTTCTTCCTGGAGTGC-3', 5'-TCCTG CAGTGGCACCATCCA-3' (Life Technologies, Gibco BRL). For reverse transcription the Superscript II kit (Life Technologies, Gibco BRL) was used. For the PCR, the PCR Core Kit (Roche Diagnostics GmbH) was used. Amplification cycles consisted of $45 \mathrm{~s}$ at $93{ }^{\circ} \mathrm{C}, 45 \mathrm{~s}$ at $55^{\circ} \mathrm{C}$ and $1 \mathrm{~min}$ at $72{ }^{\circ} \mathrm{C}$ for 30 cycles. PCR reaction was performed on a PCR thermo cycler (MJ Research). Products were analyzed electrophoretically on $1 \%$ agarose gel with ethidium bromide.

\section{Calcium signalling assay}

Concentrations of calcium ions were determined by flow cytometry on FACS Calibur (Becton Dickinson, USA), using the Fluo-4 and FuraRed probes (Molecular Probes, Eugene, Oregon, USA). Combined cellular loading permits a sensitive ratiometric assay using visual illumination.

Cells MDA MB-231 ( $10^{6}$ cells per sample) were washed two times and loaded with $4 \mu \mathrm{l}$ of $100 \mathrm{mM}$ Probenecid, $1 \mu \mathrm{l}$ FuraRed and $0.4 \mu \mathrm{l}$ Fluo-4 in the dark for $15 \mathrm{~min}$ at room temperature. The cells were washed, resuspended and put in the dark for $15 \mathrm{~min}$ at room temperature and then for $15 \mathrm{~min}$ at $37^{\circ} \mathrm{C}$. Finally, the cell suspensions were measured and the data were compared before and after activation by trypsin in a final concentration of $10^{-7} \mathrm{M}$ and by agonistic peptide (SLIGKV, Neosystem SA, France) in a final concentration $10^{-5} \mathrm{M}$. As a positive specific control of calcium signaling, ionomycin was used in the concentration $1 \mu \mathrm{g} / 100 \mu \mathrm{l}$ (Calbiochem, San Diego, California, USA).

\section{Cell count assay}

Cell growth analysis of the MDA MB-231 breast cancer cell line was carried out in the same manner as the cell cultures themselves in the cell culture wells. Into each well, $400 \mu \mathrm{l}$ of the culture medium with cell suspension of $10^{6}$ cells $/ \mathrm{ml}$ was randomly injected into the each well. After one-day preincubation in the DMEM high glucose medium containing $10 \%$ FCS and 
gentamicin solution, cells were incubated for three days: a) DMEM high-glucose medium containing $10 \%$ FCS and gentamicin solution in the presence of trypsin in PBS in a final concentration $10^{-7} \mathrm{M}, \mathrm{b}$ ) DMEM high-glucose medium containing gentamicin solution without FCS in the presence of trypsin in PBS in a final concentration $10^{-}$ ${ }^{7} \mathrm{M}$, c) DMEM high-glucose medium containing $10 \%$ FCS and gentamicin solution in the presence of PBS without trypsin, d) DMEM high-glucose medium containing gentamicin solution without FCS in the presence of PBS without trypsin.

Finally, the cells were washed with PBS and trypsinized with $0.25 \%$ trypsin solution. After this the cell suspension was measured by flow cytometry using FACS Calibur (Becton Dickinson, USA) under standard flow for $120 \mathrm{~s}$. The average count of cells incubated in the common DMEM high-glucose medium containing FCS without trypsin was used as a standard and all individual measurements were compared in percentage of this standard. Each group of measurements was performed in a cell suspension from six wells. The results were obtained from three independent experiments.

\section{Cell metabolism assay}

Metabolic activity of MDA MB-231 breast cancer cells was determined by a colorimetric MTT cell proliferation assay. MDA MB-231 cells were cultured in 96-well plates in a M1H medium supplemented with $10 \%$ FCS. Briefly, after one-day preincubation cells were maintained for 1,2 or 3 days in $\mathrm{M} 1 \mathrm{H}$ or HBSS media in the presence or absence of trypsin (see below) at $37{ }^{\circ} \mathrm{C}, 10 \mu \mathrm{l}$ of MTT (3-/4,5-dimethylthiazol-2-yl/2,5,diphenyltetrazolium bromide, Sigma) solution $(0.5 \mathrm{mg} / \mathrm{ml})$ in PBS (phosphate-buffered saline) were added and $6 \mathrm{~h}$ later $100 \mu \mathrm{l}$ of $10 \%$ SDS solution (lauryl sulfate) $\mathrm{pH} 5.3$ were added for overnight incubation. The intensity of blue color dependent on the mitochondrial enzyme succinyl dehydrogenase activity of cells in individual wells was measured by an ELISA reader (spectophotometry) at $570 \mathrm{~nm}$.

\section{Statistics}

Student's t-test and standard deviation (S.D.) were used for statistical analysis. For all tests $p<0.05$ value was considered as statistically significant.

All experimental research procedures reported in the manuscript have been approved by the appropriate ethics committee and in compliance with the Helsinki Declaration.

\section{Results}

\section{Immunohistochemistry}

Different intensity of specific diffuse intracellular cytoplasmatic positivity of PAR-2 was observed in tumor cells of all breast cancer samples (Fig. 1a). Positive immunostaining of cancer cells in bioptic specimens was independent of the histopathological grade or the expression of other prognostic factors (progesterone and estrogen receptors). Positive immunostaining of stromal fibroblasts was also observed in evaluated tissue samples. Non-neoplastic connective tissue of the breast was constantly negative.

\section{Western-blot analysis}

Western-blot analysis confirms immunohistochemical positivity of expression of PAR-2 in breast cancer samples and tissue culture cells MDA MB-231. MCF-7 cultured cells as an additional model of breast cancer cell line also showed strong positivity (Fig. 2).

\section{$R T P C R$}

AR-2 mRNA presence was observed in breast cancer samples and in tissue culture cells MDA MB-231. MCF-7 breast cancer cell line confirmed the expression of detectable amount of mRNA in the models of breast cancer cell lines (Fig. 3).

\section{$\mathrm{Ca}^{2+}$ mobilization assay}

Activation of PAR-2 was observed in MDA MB-231 cells using flow cytometric method. Figure 4a demonstrates $\mathrm{Ca}^{2+}$ mobilization after addition of trypsin in a final concentration $10^{-7} \mathrm{M}$. Figure $4 \mathrm{~b}$ demonstrates $\mathrm{Ca}^{2+}$ mobilization after addition trypsin agonistic peptide (SLIGKV) in final concentration $10^{-5} \mathrm{M}$, ionomycin in concentration $1 \mu \mathrm{g} / 100 \mu \mathrm{l}$ was used as a positive specific control.

\section{Cell metabolism assay}

Figure 5 presents an exemplary result of three independent experiments with the same trend. Arbitrary units were used for the spectrophotometric optic density evaluation.

As anticipated, a significant difference was found between the cells maintained in the medium containing $10 \%$ FCS $(\mathrm{M} 1 \mathrm{H})$ or missing $10 \%$ FCS (HBSS). In the FCS-free HBSS medium, continuous (linear) decrease of metabolic activity with a significant difference between the groups treated or non-treated with $10^{-7} \mathrm{M}$ trypsin (Fig. 5a) was observed. Higher metabolic 


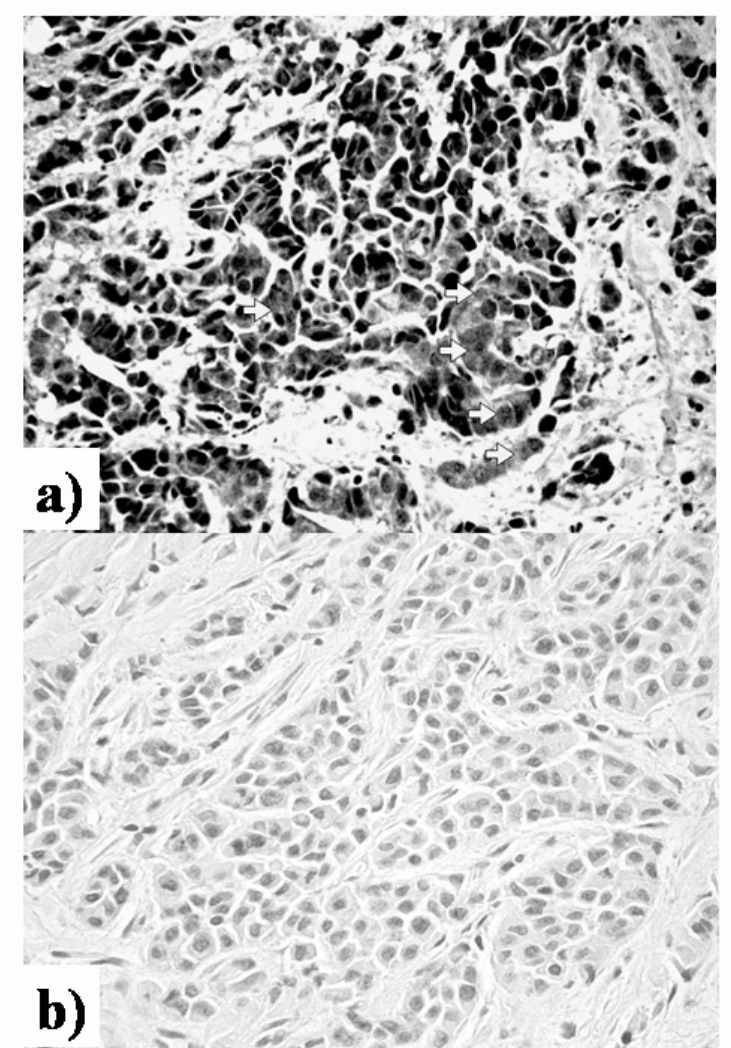

Fig. 1. a) Immunohistochemical positivity of PAR-2 on the samples of infiltrative ductal breast cancer. Diffuse intracellular positivity has been observed (arrows). b) Negative control slide of breast cancer sample incubated with nonspecific isotypematched primary antibodies and with secondary antibody, only. Original magnification 400x.

activity was recorded in the trypsin group. Similarly, in the medium containing FCS $(\mathrm{M} 1 \mathrm{H})$, a significant difference between the groups treated or non-treated with $10^{-7} \mathrm{M}$ trypsin has been recorded since the day 2 , higher metabolic activity being present in trypsin group (Fig. 5b). In contrast to the HBSS groups, cells growing in $\mathrm{M} 1 \mathrm{H}$ medium with trypsin tended to retain higher metabolic activity even after 3 days of exposure in comparison with the trypsin-free group, where a linear decrease of metabolic activity was recorded similarly to the HBSS groups. Higher metabolic activity of cells in the trypsin-treated groups was observed despite the decrease of cell growth observed in the cell count assay in the serum-free medium.

\section{Cell morphology analysis}

As the activity of trypsin was blocked by the serum trypsin inhibitors present in FCS, no difference was observed between cells cultured with trypsin in PBS in

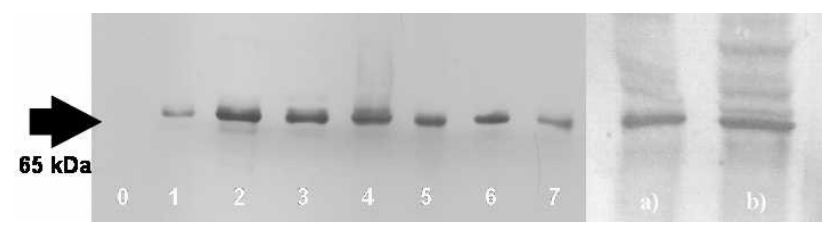

Fig. 2. Western blot analysis demonstrates presence of PAR-2 in samples of breast cancer patients (1-7) and in samples of tissue culture cells MDA MB-231 (a) and MCF-7 (b). Zero line indicates breast cancer sample incubated without primary antibody. Arrow indicates analysis of PAR-2 expressed in samples (65 kDa).

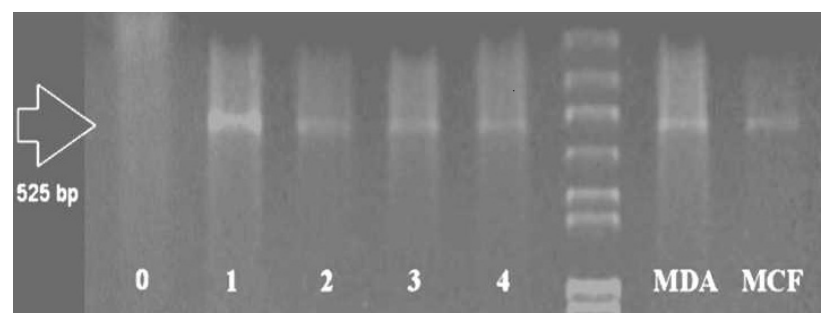

Fig. 3. RT PCR products of 525bp demonstrate presence of mRNA of PAR-2 in samples of breast cancer patients (1-4) and in samples of tissue culture cells MDA-MB-231 and MCF-7. Zero line demonstrates negative control of PCR reaction.

final concentration $10^{-7} \mathrm{M}$ or cultured in the DMEM high-glucose medium containing of $10 \%$ FCS and gentamicin solution with the PBS only served as a control (Figs 6a,c,d). Their shape was regularly elongated, typical for normally cultured cells of MDA MB-231 cells. In the DMEM high glucose medium containing only gentamicin solution, without FCS, in the presence of trypsin, the cells changed their shape to round, small, poorly adhering cells compared to the controls (Fig. 6b). The total number of cells was reduced in both serum-free groups.

\section{Cell count assay}

The cell growth of the MDA MB-231 breast cancer cell line in the full DMEM high glucose medium containing $(a, c)$ or missing $(b, d) 10 \%$ FCS with $(a, b)$ or without (c, d) trypsin is summarized in Figure 7. There was no significant difference in the cell growth in groups growing in DMEM high-glucose medium containing FCS with (a, $96.1 \pm 19.3 \%, \quad$ mean \pm S.D. $) \quad$ or without (c, $100 \pm 17.8 \%) 10^{-7} \mathrm{M}$ trypsin.

Cells growing in DMEM high-glucose medium without FCS with (b, 12.3 $\pm 4.5 \%$ ) or without $10^{-7} \mathrm{M}$ trypsin ( $d, 41.9 \pm 22.5 \%)$ showed a significant difference in the cell number after 3-day incubation (Fig. 7). The absence of FCS changed the cell number during the short term 3-day cultivation. 


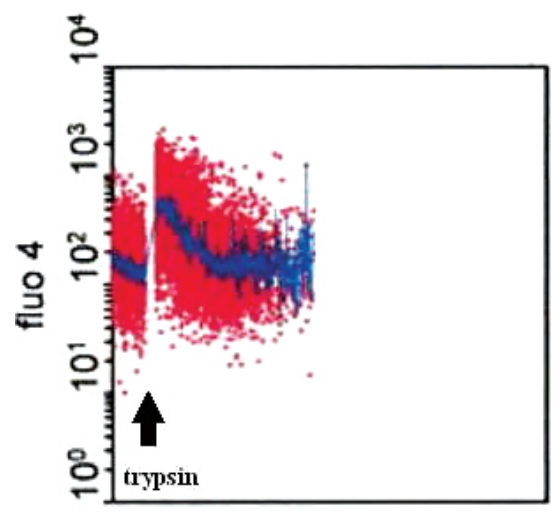

Time $(512.00 \mathrm{sec}$.

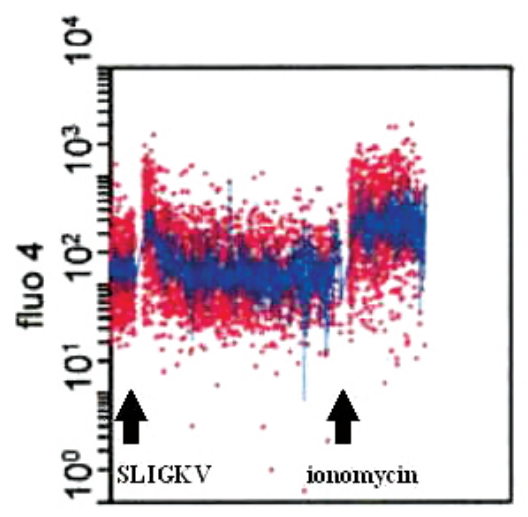

Time $(512.00 \mathrm{sec}$.
Fig. 4. $\mathrm{Ca}^{2+}$ mobilization analysis. Activation of PAR-2 has been followed on MDA MB231 cells using the flow cytometric method. Left panel shows $\mathrm{Ca}^{2+}$ mobilization after trypsin activation in concentration of $10^{-7} \mathrm{M}$. Right panel demonstrates $\mathrm{Ca}^{2+}$ mobilization after PAR-2 agonistic peptide (SLIGKV) activation in concentration of $10^{-5} \mathrm{M}$. Ionomycin in concentration $1 \mu \mathrm{gg} / 100 \quad \mu \mathrm{l}$ served as a positive control.

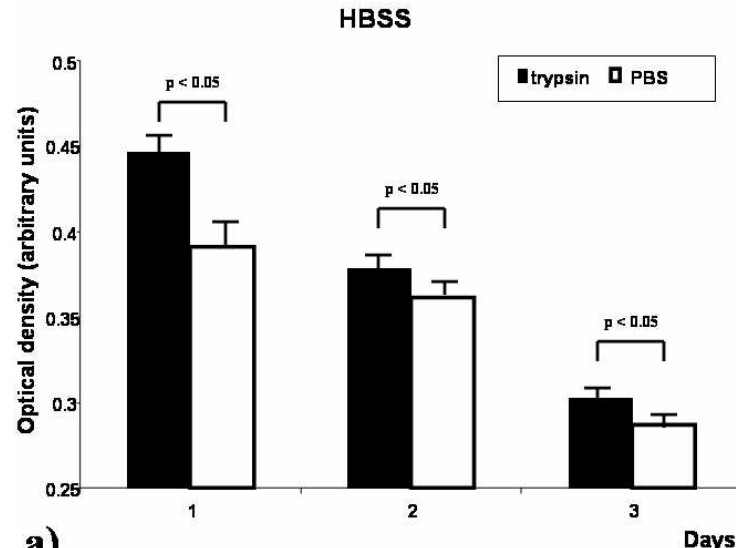

a)

Days

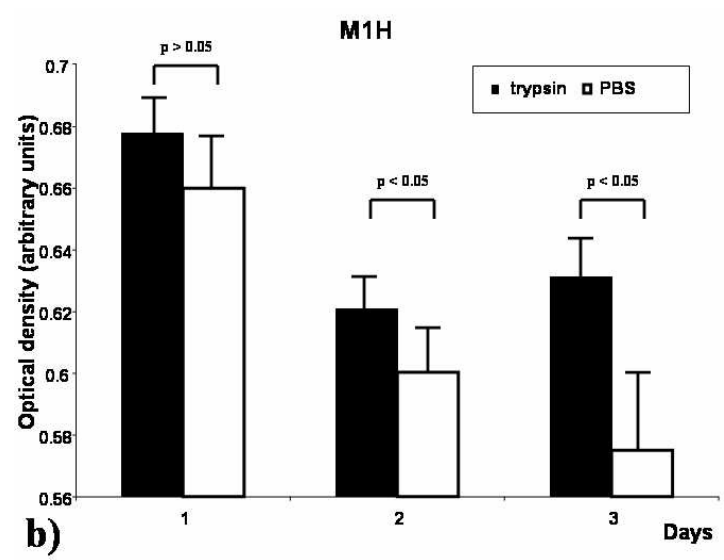

Fig. 5. Cell metabolism assay shows a significant difference of metabolic activity of the cancer cell line MDA MB-231 in serum-free medium (HBSS) with and without trypsin (a) and in a medium containing serum (M1H) with and without presence of trypsin (b).

\section{Discussion}

Our results demonstrate that PAR-2 is expressed in breast cancer. PAR-2 was detected on the protein and also on mRNA levels in breast cancer cell lines. In bioptic tissue samples, the expression of PAR-2 was detected independently the histopathological grade of tumor, estrogen and progesterone receptor expression or other prognostic factors. We also observed the influence of trypsin on metabolic activity and growth of the cell line isolated from breast cancer. This observation suggests a possible increased expression of PAR-2 in breast cancer tissues and its interaction with trypsin to the initiation and/or progression of breast cancer. Our observation confirms the previous study of D'Andrea et al. (2001) presenting immunohistochemical positivity of breast cancer cells and stromal fibroblasts in breast cancer patient samples.

The discovery of PAR-2 receptor started the process of partial elucidation of the potential role of trypsin in cellular signaling, tissue growth and/or malignant transformation (Nystedt et al. 1994, 1995). It was demonstrated that tumor-associated trypsin (TAT) is involved in the protease cascade stimulating tumor cell invasion and degradation of extracellular matrix in different cell lines (Koivunen et al. 1991). Previous studies demonstrated increased expression of PAR-2 in different malignant tissues and cell lines, including digestive tract cancer, sarcomas, leukemias, lymphomas and also malignant brain tumors of astrocytic origin (Steinhoff et al. 2005).

In recent studies, PAR-2 activation in IL-3dependent murine lymphoma cell line BaF-3 resulted in cell proliferation (Mirza et al. 1997). However, the data obtained so far are still controversial. After the trypsinogen-1 cDNA introduction in the gastric carcinoma cell line MKN-1, Miyata et al. (1998) demonstrated the stimulation of cellular growth and 


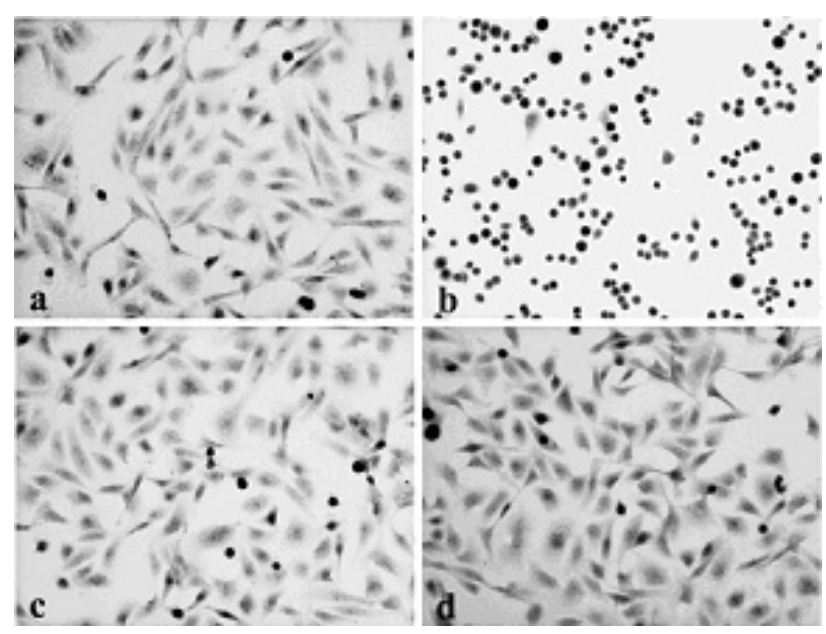

Fig. 6. Three days incubation of MDA MB- 231 breast cancer cells in the DMEM high-glucose medium containing $10 \%$ FCS and $1 \%$ gentamicin solution in the presence of $10^{-7} \mathrm{M}$ trypsin in PBS (a) or PBS only (c) as a control. No difference between the two groups has been observed. Three days incubation of MDA MB-231 breast cancer cells in the DMEM high-glucose medium containing only $1 \%$ gentamicin solution without FCS in the presence of $10^{-7} \mathrm{M}$ trypsin in PBS (b) or PBS only (d) as a control. In the presence of trypsin, the cells change their shape to round, small poorly adhering. This change has not been observed in the absence of trypsin. The total amount of cells was reduced in both serum-free groups.

adhesion to fibronectin and vitronectin when trypsinogen activator enterokinase was added into the culture. In vivo (intraperitonealy) transplanted, these transfected $\mathrm{MKN}-1$ cells produced solid tumors in adjacent organs (Miyata et al. 1998). In the above mentioned MKN-1 cells, Miyata et al. (2000), demonstrated that trypsin stimulates integrin alfa5beta1-dependent adhesion to fibronectin and proliferation through the activation of PAR-2.

Another study with a STKM-1 gastric cancer cell line demonstrated that production of trypsin correlates with their malignant phenotype and invasive growth (Kato et al. 1998). In human colon cancer cells, proliferation was initiated by trypsin acting on PAR-2 (Darmoul et al. 2001). These authors suggested that trypsin could be considered as a growth factor. The same authors showed that colon cancer cell lines secrete trypsin in concentrations compatible with activation of PAR-2. They suggested possible autocrine/paracrine regulation of PAR-2 acting by trypsin in colon cancer cells (Ducroc et al. 2002). The PAR-2 agonist peptide SLIGKV and trypsin also significantly increased cell proliferation in three pancreatic cancer cell lines SW1990, Capan-2, and Panc-1. Under the conditions in vivo, subcutaneously xenografted tumors showed significantly enhanced

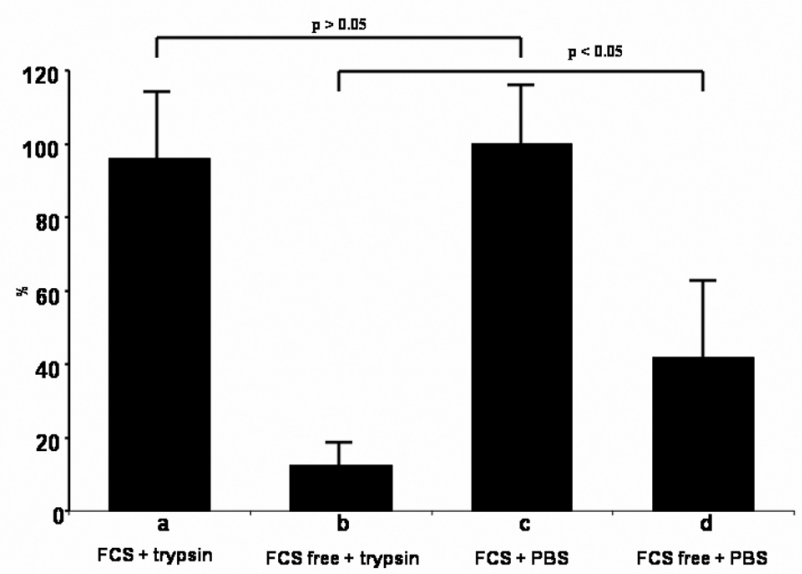

Fig. 7. The cell growth of the MDA MB-231 breast cancer cell line in the full DMEM high-glucose medium containing $(a, c)$ or missing (b, d) $10 \%$ FCS with (a, b) or without (c, d) trypsin. There was no significant difference $(p>0.05)$ found in the cell growth in groups growing in DMEM high-glucose medium containing FCS with (a) or without (c) $10^{-7} \mathrm{M}$ trypsin. On the contrary, cells growing in DMEM high-glucose medium without FCS with (b) or without (d) $10^{-7} \mathrm{M}$ trypsin showed significant difference in the cell amount after 3-day incubation.

growth after treatment with an agonist peptide (Shimamoto et al. 2004). Thus PAR-2 activated by trypsin plays an important role in promoting proliferation of pancreatic cancer. Recently, Ge et al. (2004) presented that secretion of trypsin-like protease and its autocrine activation of PAR-2 in the breast cancer cell line MDA MB-231 influences cell migration.

Our results showed that PAR-2 expressed in the breast cancer cell line MDA MB-231 is activated by trypsin and agonistic peptide SLIGKV. Our results also demonstrate that trypsin inhibitors present in blood serum influence the action of trypsin on cultured cells. These results suggest that trypsin in the investigated concentration does not have a significant influence on the growth of MDA MB-231 breast cancer cell line under physiological conditions, when extracellular fluid containing serum with protease inhibitors is present. This suggests that different activity of proteinases and a different consequent response of PAR-2 can be observed in certain human tissue compartments (blood, tumor environment, interstitium) in vivo. From this point of view, the activity of the agonistic peptide does not seem to play an important role in physiological processes of cell regulation and "real" trypsin or trypsin-like activity. The general role of PAR-2 in cancer initiation and development has to be evaluated in the presence/absence of natural inhibitors. Although the PAR-2 activation by trypsin is predominantly considered as stimulating tumor 
cell growth and invasiveness, inhibitory effect on tumor cell growth has also been reported. For instance, activation of PAR-2 on CAPA-2 pancreatic cancer cell line decreases ${ }^{3} \mathrm{H}$-thymidine incorporation into the cell related to inhibition of tumor cell growth (Kaufmann et al. 1998). Similarly, PAR-1, receptor of the same family activated by thrombin, is a potential tumor cell proliferating and invading agent (Wojtukiewicz et al. 1993, Henrikson et al. 1999). Another study demonstrated that PAR-1 signaling inhibits migration and invasion of breast cancer cells (Kamath et al. 2001). The findings of Yamashita et al. (2003) also support the notion that trypsin plays a tumor-suppressive role in human carcinomas, as they found reduced production of trypsinogen accompanied by reduced PAR-2 expression in esophageal squamous cell carcinomas and 72 gastric adenocarcinomas.

The controversy between the decrease of growth activity and morphology alteration in comparison with the significant increase of metabolic activity of the cells should also be pointed out. It is well known that trypsin reduces adhesion and in higher concentration is used for dehiscence of cells in cultures. We have treated cell cultures with ten times lower concentrations, which did not cause complete dehiscence of cells from the surface, but elicited the morphology changes and adhesion alteration (reduced area of the cell connection with the surface in trypsin treated cells without FCS). The cell metabolic activity remained higher in trypsin treated cells. This observation suggests that adherence to surface or presence of connective tissue environment is one of essential conditions for proliferation of cancer cells without affecting metabolic activity of these cells. From this point of view, the role of PAR-2 in the expression of adhesion molecules is an essential question for future experiments. On the contrary, triggering of the dendritic, antigen-presenting, cell development from the bone marrow progenitor cells, PAR-2 could increase general antitumor immunity (Fields et al. 2003). These controversial results remain for further investigation of the role of PARs in the process of tumor cell migration, invasiveness and metastasis formation.

\section{Conclusions}

PAR-2 is expressed in breast cancer tissues independently of routinely investigated prognostic factors. PAR-2 is expressed in breast cancer cell lines. In in vitro conditions, PAR-2 is activated by trypsin and by agonistic peptide as well as in the model of breast cancer cell line MDA MB-231. Activation of PAR-2 in vitro increases the proliferative activity of breast cancer cell lines MDA MB-231 and this activation is modified in the presence of serum as a potential source of protease inhibitors. The ambivalent function of PAR-2 in different cells complicates real interpretation of the function of this receptor in cancer development, progression and metastasis. PAR-2 acts as Dr. Jekyll in the case when activating bone marrow progenitor cells triggers dendritic cells development by supporting antigen presentation and possible reduction of adhesion of cancer cells to the surface. This effect could cause the reduction of metastatic dissemination potential; decrease of ${ }^{3} \mathrm{H}$-thymidine incorporation into the cell has also been discussed above. However, supporting cancer cell metabolism and tumor progression PAR-2 activation acts as Mr. Hyde at the same time.

\section{Acknowledgements}

The authors gratefully acknowledged support of the League Against Cancer Prague for obtaining some critical equipment and dr. Zdeněk Kostrouch for providing some chemicals and equipment for cell line experiments.

\section{Abbreviations}

PAR-2 - Proteinase-activated receptor-2, DMEM Dulbecco's Modified Eagle Medium, FCS - Fetal calf serum, SDS-PAGE - Sodium dodecyl sulphate polyacrylamide gel electrophoresis

\section{References}

CEDERQVIST K, HAGLUND C, HEIKKILA P, SORSA T, TERVAHARTIALA T, STENMAN UH, ANDERSSON S: Pulmonary trypsin-2 in the development of bronchopulmonary dysplasia in preterm infants. Pediatrics 112: 570-577, 2003.

D'ANDREA MR, DERIAN CK, SANTULLI RJ, ANDRADE-GORDON P: Differential expression of proteaseactivated receptors-1 and -2 in stromal fibroblasts of normal, benign, and malignant human tissues. $A m J$ Pathol 158: 2031-2041, 2001. 
DARMOUL D, MARIE JC, DEVAUD H, GRATIO V, LABURTHE M: Initiation of human colon cancer cell proliferation by trypsin acting at protease-activated receptor-2. Br J Cancer 85: 772-779, 2001.

DUCROC R, BONTEMPS C, MARAZOVA K, DEVAUD H, DARMOUL D, LABURTHE M: Trypsin is produced by and activates protease-activated receptor-2 in human cancer colon cells: evidence for new autocrine loop. Life Sci 70: 1359-1367, 2002.

FIELDS RC, SCHOENECKER JG, HART JP, HOFFMAN MR, PIZZO SV, LAWSON JH: Protease-activated receptor-2 signaling triggers dendritic cell development. Am J Pathol 162: 1817-1822, 2003.

GE L, SHENOY SK, LEFKOWITZ RJ, DEFEA K: Constitutive protease-activated receptor-2-mediated migration of MDA MB-231 breast cancer cells requires both beta-arrestin-1 and -2. J Biol Chem 279: 55419-55424, 2004.

HENRIKSON KP, SALAZAR SL, FENTON JW 2ND, PENTECOST BT: Role of thrombin receptor in breast cancer invasiveness. Br J Cancer 79: 401-406, 1999.

HOJILLA CV, MOHAMMED FF, KHOKHA R: Matrix metalloproteinases and their tissue inhibitors direct cell fate during cancer development. Br J Cancer 89: 1817-1821, 2003.

KAMATH L, MEYDANI A, FOSS F, KULIOPULOS A: Signaling from protease-activated receptor-1 inhibits migration and invasion of breast cancer cells. Cancer Res 15: 5933-5940, 2001.

KAUFMANN R, SCHAFBERG H, NOWAK G: Proteinase-activated receptor-2-mediated signaling and inhibition of DNA synthesis in human pancreatic cancer cells. Int J Pancreatol 24: 97-102, 1998.

KATO Y, NAGASHIMA Y, KOSHIKAWA N, MIYAGI Y, YASUMITSU H, MIYAZAKI K: Production of trypsins by human gastric cancer cells correlates with their malignant phenotype. Eur J Cancer 34: 1117-1123, 1998.

KOIVUNEN E, RISTIMAKI A, ITKONEN O, OSMAN S, VUENTO M, STENMAN UH: Tumor-associated trypsin participates in cancer cell-mediated degradation of extracellular matrix. Cancer Res 51: 2107-2112, 1991.

LEEMAN MF, CURRAN S, MURRAY GI: New insights into the roles of matrix metalloproteinases in colorectal cancer development and progression. J Pathol 201: 528-534, 2003.

MACFARLANE SR, SEATTER MJ, KANKE T, HUNTER GD, PLEVIN R: Proteinase-activated receptors: Pharmacol Rev 53: 245-282, 2001.

MINN A, SCHUBERT M, NEISS WF, MULLER-HILL B: Enhanced GFAP expression in astrocytes of transgenic mice expressing the human brain-specific trypsinogen IV. Glia 22: 338-347, 1998.

MIRZA H, SCHMIDT VA, DERIAN CK, JESTY J, BAHOU WF: Mitogenic responses mediated through the proteinase-activated receptor-2 are induced by expressed forms of mast cell alpha- or beta-tryptases. Blood $\mathbf{9 0}$ : 3914-3922, 1997.

MIYATA S, MIYAGI Y, KOSHIKAWA N, NAGASHIMA Y, KATO Y, YASUMITSU H, HIRAHARA F, MISUGI K, MIYAZAKI K: Stimulation of cellular growth and adhesion to fibronectin and vitronectin in culture and tumorigenicity in nude mice by overexpression of trypsinogen in human gastric cancer cells. Clin Exp Metastasis 16: 613-622, 1998.

MIYATA S, KOSHIKAWA N, YASUMITSU H, MIYAZAKI K: Trypsin stimulates integrin alpha(5)beta(1)dependent adhesion to fibronectin and proliferation of human gastric carcinoma cells through activation of proteinase-activated receptor-2. J Biol Chem 275: 4592-4598, 2000.

NYSTEDT S, EMILSSON K, WAHLESTEDT C, SUNDELIN J: Molecular cloning of a potential proteinase activated receptor. Proc Natl Acad Sci USA 91: 9208-9212, 1994.

NYSTEDT S, EMILSSON K, LARSSON AK, STROMBECK B, SUNDELIN J: Molecular cloning and functional expression of the gene encoding the human proteinase-activated receptor 2. Eur J Biochem 232: 84-89, 1995.

ROSAI J: Carcinoma of the breast. In: Rosai and Ackerman's Surgical Pathology, ROSAI J (ed), 9th edition, vol 2, Mosby, Elsevier, New York, 2004, pp 1787-1876.

ROSHY S, SLOANE BF, MOIN K: Pericellular cathepsin B and malignant progression. Cancer Metastasis Rev 22: 271-286, 2003.

SHIMAMOTO R, SAWADA T, UCHIMA Y, INOUE M, KIMURA K, YAMASHITA Y, YAMADA N, NISHIHARA T, OHIRA M, HIRAKAWA K: A role for protease-activated receptor-2 in pancreatic cancer cell proliferation. Int J Oncol 24: 1401-1406, 2004. 
SMITH-SWINTOSKY VL, CHEO-ISAACS CT, D 'ANDREA MR, SANTULLI RJ, DARROW AL, ANDRADEGORDON P: Protease-activated receptor-2 (PAR-2) is present in the rat hippocampus and is associated with neurodegeneration. J Neurochem 69: 1890-1896, 1997.

STEINHOFF M, BUDDENKOTTE J, SHPACOVITCH V, RATTENHOLL A, MOORMANN C, VERGNOLLE N, LUGER TA, HOLLENBERG MD: Proteinase-activated receptors: transducers of proteinase-mediated signaling in inflammation and immune response. Endocr Rev 26: 1-43, 2005.

UCHIMA Y, SAWADA T, NISHIHARA T, UMEKAWA T, OHIRA M, ISHIKAWA T, NISHINO H, HIRAKAWA $\mathrm{K}$ : Identification of a trypsinogen activity stimulating factor produced by pancreatic cancer cells: its role in tumor invasion and metastasis. Int J Mol Med 12: 871-878, 2003.

WOJTUKIEWICZ MZ, TANG DG, CIARELLI JJ, NELSON KK, WALZ DA, DIGLIO CA, MAMMEN EF, HONN KV: Thrombin increases the metastatic potential of tumor cells. Int J Cancer 54: 793-806, 1993.

YAMASHITA K, MIMORI K, INOUE H, MORI M, SIDRANSKY D: A tumor-suppressive role for trypsin in human cancer progression. Cancer Res 63: 6575-6578, 2003.

\section{Corresponding author}

T. Olejár, Institute of Biophysics, First Medical Faculty, Charles University, Salmovská 1, 12000 Prague 2, Czech Republic. E-mail: tomas.olejar@seznam.cz 